\title{
CINEMA, IDEOLOGIA E CONSUMO: UMA REFLEXÃO SOBRE O FILME "QUE HORAS ELA VOLTA?"
}

\author{
Cinema, ideology and consumption: a study about the movie "Que horas ela \\ volta?"
}
Cine, ideología y consumo:una reflexión sobre la película "Que horas ela volta?"

\author{
Beatriz Braga Bezerra \\ Publicitária e doutora pelo PPGCOM-ESPM \\ beatriz.braga@hotmail.com
}

Dorama de Miranda Carvalho

Jornalista e doutora pelo PPGCOM-ESPM

dora.carvalho@gmail.com

\section{Resumo}

O presente trabalho tem como objetivo compreender de que forma o cinema pode funcionar como instrumento ideológico sob o ângulo dos Estudos Culturais. Os aportes teóricos utilizados perpassam conceitos de hegemonia e ideologia trabalhados por Ana Carolina Escosteguy (2001) e Stuart Hall (1997); os fundamentos dos Estudos Culturais por meio de Jesús Martín-Barbero e Germán Rey (2004); o debate sobre a cultura da mídia levantado por Douglas Kellner (2001); e as contribuições sobre o processo de identificação que ocorre no cinema a partir de Béla Baláz (1945) e sobre a construção da diegese fílmica caracterizada por Étienne Souriau (1953), entre outros. Discutimos ainda, a partir de Néstor García Canclini (2008; 2012), as dinâmicas de comunicação e consumo apresentadas no filme Que horas ela volta? (Anna Muylaert, 2015), buscando evidenciar como se configura o papel do cinema frente às lutas ideológicas e mediante um universo de representações sociais oriundas do ato de consumir.

Palavras-chave: Comunicação e Consumo; Estudos Culturais; Que horas ela volta?.

\section{Abstract}

This paper aims to understand how cinema can operate as an ideological instrument under the Cultural Studies angle. The theoretical contributions used to indicate the concepts of hegemony and ideology are sustained by Ana Carolina Escosteguy (2001) and Stuart Hall (1997); Our debate is supported by Jesús Martín-Barbero and Germán Rey (2004); the culture of the media discussed by Douglas Kellner (2001); and contributions on the identification process that takes place in the cinema from Béla Baláz (1945) and on the construction of filmic diegesis characterized by Étienne Souriau (1953). We also discuss, from Néstor García Canclini $(2008,2012)$, the communication and consumption dynamics presented in the movie Que horas ela volta? (Anna Muylaert, 2015), to demonstrate how cinema is configured in the 
face of ideological struggles and through a scene of social representations derived from the act of consuming.

Key words: Communication and Consumption; Cultural Studies; Que horas ela volta?.

\section{Resumen}

Este estudio tiene como objetivo comprender cómo la película puede funcionar como un instrumento ideológico desde la perspectiva de los estudios culturales. El marco teórico utilizado impregnan los conceptos de hegemonía y la ideología trabajadas por Ana Carolina Escosteguy (2001) y Stuart Hall (1997); las bases de nuestro estudio son suportadas por Martín Barbero y Germán Rey (2004); el debate sobre la cultura de los medios son planteadas por Douglas Kellner (2001); y las contribuciones en el proceso de identificación que ocurre en la película son discutidas por Béla Baláz (1945) y la construcción de la narración fílmica son caracterizadas por Étienne Souriau (1953). Néstor García Canclini $(2008 ; 2012)$ nos ayuda a discutir la dinámica de la comunicación y el consumo presentados en la película Que horas ela volta? (Anna Muylaert, 2015), y el objetivo es presentar la configuración del papel del cine en las luchas ideológicas y por medio de uma escena de representaciones sociales derivados del acto de consumir.

Palabras clave: Comunicación y el consumo; Estudios culturales; Que horas ela volta?

\section{INTRODUÇÃO}

As narrativas são fundamentais para a existência do ser humano; é por meio delas que organizamos e articulamos as múltiplas impressões que temos da realidade, possibilitando a reflexão sobre nós mesmos no presente, no passado e no futuro. Dessa forma, Paul Auster (2001) defende que não seria possível viver sem as histórias.

Jerome Bruner (1991) explica que as narrativas permitem a construção da realidade pelos sujeitos, uma vez que narrar é uma das maneiras que o pensamento humano se organiza. E fazemos isso desde as nossas infâncias, porque as narrativas nos ajudam a atribuir sentido ao mundo que nos cerca. Para Marcela Chacel (2012, p.62), é por esse motivo que sempre “organizamos nossas experiências e memórias dos acontecimentos das nossas vidas por meio de narrativas: histórias, mitos, 'desculpas', anedotas, razões para fazer ou não fazer algo". Roland Barthes (1976) resgata um pouco de sua origem:

A narrativa está presente em todos os tempos, em todos os lugares, em todas as sociedades; a narrativa começa com a própria história da humanidade; não há em parte alguma povo algum sem narrativa; todas as classes, todos os grupos humanos têm suas narrativas, e frequentemente estas narrativas são apreciadas em comum por homens de culturas diferentes, e mesmo opostas (BARTHES, 1976, p. 19). 
Atualmente vemos que a mídia se utiliza de narrativas e imagens para disseminar mitos e símbolos que irão construir uma cultura comum para as pessoas, como afirma Douglas Kellner (2001, p.9). Os produtos midiáticos indicam os modelos de sucesso e contribuem na formatação de valores morais. Essa cultura disseminada pela mídia é industrial: mistura emoções e ideias buscando arrebatar grandes audiências e atrair o lucro (ibidem, p.9).

\begin{abstract}
As narrativas são eficazes ferramentas para transmitir ideias e eficientes ferramentas de comunicação. Isso se dá porque, no que diz respeito à questão simbólico-cultural, as narrativas fornecem interpretações para o nosso cotidiano social e significados culturais, atribuindo, desse modo, sentido e identidade à existência humana, ambos fundamentais para o homem e a coletividade compreenderem sua condição de vida e dominarem seu ambiente (CHACEL, 2012, p.67).
\end{abstract}

As narrativas se utilizam, então, dos fatos do cotidiano para construir interpretações que podem manter ou promover a transformação social. Elas servem também como motivadoras do debate e do conhecimento, impulsionando a difusão cultural e científica. Para Tzvetan Todorov (1976) as narrativas podem se colocar tanto como história quanto como discurso. História porque evocam elementos da realidade e personagens que podem se confundir com pessoas da vida real; e discurso porque se constituem da transmissão a partir de um narrador e um receptor, podendo ser relatada por diversos meios: um livro, um filme ou até mesmo pela oralidade (BEZERRA, 2014).

A partir dessa discussão teórica, este estudo tem por objetivo compreender melhor de que forma o cinema pode funcionar como instrumento ideológico. Para avançarmos no debate, pontuamos argumentos sobre os conceitos de hegemonia e ideologia articulados por Ana Carolina Escosteguy (2001) e Stuart Hall (1977), assim como a proposta de um processo de identificação no cinema conforme explica Béla Baláz (1945) e a relevância da diegese fílmica caracterizada por Étienne Souriau (1953). Tal reflexão tem como ponto de partida o questionamento do papel do cinema sob o ângulo dos Estudos Culturais, tomando por base o texto de Jesús Martín-Barbero e Germán Rey (2004) em consonância com o debate promovido por Douglas Kellner (2001) sobre a cultura da mídia. Como culminância da pesquisa, vamos analisar o filme Que horas ela volta? (Anna Muylaert, 2015), com o objetivo de evidenciar o papel do cinema frente às lutas ideológicas. 


\title{
2 MEIOS DE COMUNICAÇÃO DE MASSA, HEGEMONIA E IDEOLOGIA
}

O cinema, enquanto espaço midiático para veiculação de narrativas fílmicas, proporciona ao público uma experiência imersiva. "No cinema, a câmera carrega o espectador para dentro do filme. Vemos tudo como se fosse do interior e estamos rodeados pelos personagens", como explica Béla Balázs (1945, apud XAVIER, 1983, p.85).

\begin{abstract}
Nosso olho, e com ele nossa consciência, identifica-se com os personagens no filme; olhamos para o mundo com os olhos deles e, por isso, não temos nenhum ângulo de visão próprio. Andamos pelo meio de multidões, galopamos, voamos ou caímos com o herói, se um personagem olha o outro nos olhos, ele olha da tela para nós. Nossos olhos estão na câmera e tornamse idênticos aos olhares dos personagens. Os personagens veem com os nossos olhos. É neste fato que consiste o ato psicológico de "identificação". Na comparável a este efeito de "identificação" já ocorreu em qualquer outra forma de arte e é aqui que o cinema manifesta sua absoluta novidade artística (ibidem,p.85).
\end{abstract}

Étienne Souriau (1953, p.7) define a diegese como todos os aspectos que compõem e caracterizam o universo ficcional como ele é; todos os elementos que pertencem à inteligibilidade da história contada. Através da composição desse universo diegético - espaço, tempo, sons, clima, cheiros, objetos e tudo mais que os personagens ali estão vivendo - o cinema, juntamente com os outros media, se utiliza do arsenal audiovisual, incluindo efeitos especiais, montagem e, mais recentemente, a tridimensionalidade e o hipercinema ${ }^{1}$ para envolver os espectadores em suas narrativas.

Martín-Barbero e Rey (2004, p.26) afirmam que a televisão ocupa um lugar estratégico "nas dinâmicas da cultura cotidiana das maiorias, na transformação das sensibilidades, nos modos de construir imaginários e identidades". Para os autores, ela constitui, com encantamento ou não, um dispositivo simultâneo de moldagem e deformação dos gostos populares e do cotidiano.

As mídias audiovisuais (cinema à maneira de Hollywood, televisão e boa parte do vídeo) constituem, ao mesmo tempo, o discurso por antonomásia da bricolagem dos tempos - que nos familiariza sem esforço, extraindo-o das complexidades e ambiguidades de sua época, com qualquer acontecimento do passado - e o discurso que melhor expressa a compressão do presente, a

\footnotetext{
${ }^{1}$ Cinema que busca o extremo de todas as sensações. Mais informações em: LIPOVETSKY, G.; SERROY, J. O ecrã global: cultura mediática e cinema na era hipermoderna. Lisboa: Edições 70, 2010.
} 
transformação do tempo extensivo da história no intensivo do instantâneo (ibidem, p.35).

Os media se tornam, então, responsáveis por fomentar a construção imagética de princípios e práticas sociais, afirma Ana Carolina Escosteguy (2001). A partir do pensamento de Stuart Hall (1977), a autora explica que essas imagens, mesmo sendo representações fragmentadas, constroem o imaginário social através de mundos, realidades e totalidades vividas por outras pessoas.

É, também, função dos media refletir e expressar uma pluralidade - mesmo que aparente - de representações ao invés de um universo ideológico unitário. Esse conhecimento social que os media seletivamente fazem circular é organizado através de sentidos preferenciais. E, por último, esse conjunto de representações, imagens e sentidos, seletivamente representado e classificado, é organizado e articulado num todo coerente, numa ordem reconhecida, ou melhor, na produção do consenso, na construção de legitimidade (ESCOSTEGUY, 2001, p.69).

Ou seja, os media selecionam e propagam um conjunto de representações organizadas visando promover a coerência em torno dos sentidos elencados como preferenciais. Os meios de comunicação constroem produtos simbólicos e assumem o papel ideológico no processo de codificação de suas mensagens (ESCOSTEGUY, 2001, p.69).

Para Kellner (2001, p.10) os espetáculos da mídia apontam aqueles que tem poder e que podem exercer força e violência: "dramatizam e legitimam o poder das forças vigentes e mostram aos não-poderosos que, se não se conformarem, estarão expostos ao risco de prisão ou morte". Ele defende que é preciso aprender a interpretar e criticar os significados e as mensagens veiculadas na mídia.

\begin{abstract}
Os meios dominantes de informação e entretenimento são uma fonte profunda e muitas vezes não percebida de pedagogia cultural: contribuem para nos ensinar como nos comportar e o que pensar e sentir, em que acreditar, o que temer e desejar - e o que não. Consequentemente, a obtenção de informações críticas sobre a mídia constitui uma fonte importante de aprendizado sobre o modo de conviver com esse ambiente cultural sedutor. Aprendendo como ler e criticar a mídia, resistindo à sua manipulação, os indivíduos poderão fortalecer-se em relação à mídia e à cultura dominantes (ibidem, p.10).
\end{abstract}

Ao aplicarmos esse raciocínio no que tange às narrativas fílmicas e o cinema enquanto meio de comunicação de massa, concluiríamos de imediato que os filmes podem promover 
representações e universos ideológicos específicos, abstendo-se de abarcar diversos outros pontos de vista e instaurando, assim, seu discurso como único e legítimo. Todavia, Hall (1977) pondera que os significados dominantes não são unitários, mas uma diversidade deles, e os codificadores - os roteiristas e diretores, no caso - selecionariam um deles para representar o todo, dentro de um horizonte da ideologia dominante.

É importante destacar o que Hall chama de descentramento do sujeito. Isso é relevante porque há a questão da subjetivação e da incorporação subjetiva da ideologia. É preciso levar em consideração ainda os sistemas de representação, aqueles significados pelos quais representamos o mundo para nós mesmo e os outros. É possível que a construção dos discursos aconteçam no campo do inconsciente desde a infância. Para o autor, podemos nos situar ideologicamente em relação ao mundo de acordo com diversos fatores e não apenas por meio de mecanismos históricos ou biológicos, “já que estamos permanentemente abertos para sermos posicionados e situados de formas distintas, em momentos diferentes de nossa existência" (HALL, 2003, p. 184). Esses são indicativos de que as representações promovidas pelo cinema podem abarcar certo número de telespectadores ou não gerar qualquer tipo de identificação e/ou reconhecimento.

É fundamental pontuar esses aspectos já que os Estudos Culturais partem em grande medida dessa premissa, de que os "discursos são múltiplos, bem como numerosas histórias distintas. Compreendem um conjunto de formações, com suas diferentes conjunturas e momentos no passado (...), mas sem cair no pluralismo simplista" (HALL, 2003, p. 201). É preciso considerar que os Estudos Culturais têm por objetivo analisar certos aspectos da natureza constitutiva e política da própria representação, de suas complexidades, dos efeitos da linguagem, da textualidade como local de vida e morte.

Escosteguy (2001, p.70) pondera que os significados não estão dados, mas são produtos de uma prática social. Dessa forma, significados diferentes podem ser atribuídos a um mesmo evento. No caso dos media, elementos sociais e simbólicos são articulados na produção de um objeto discursivo, tais como o texto jornalístico, a telenovela ou os filmes. Kellner (2001, p.11) afirma que o público - espectadores de um filme, por exemplo - pode “criar sua própria leitura e seu próprio modo de apropriar-se da cultura de massa, usando a sua cultura como recurso para fortalecer-se e inventar significados, identidade e forma de vida próprios". 


\begin{abstract}
A própria mídia dá recursos que os indivíduos podem acatar ou rejeitar na formação de sua identidade em oposição aos modelos dominantes. Assim, a cultura veiculada pela mídia induz os indivíduos a conformar-se à organização vigente da sociedade, mas também lhes oferece recursos que podem fortalecê-los na oposição a essa mesma sociedade (ibidem, p.11-12).
\end{abstract}

Mas, exatamente por essa dubiedade presente na cultura midiática, Hall (1994) sintetiza a queda da passividade absoluta das audiências ao afirmar sua descrença nos significados únicos.

\begin{abstract}
Para ser perfeitamente hegemônico é ter cada sentido que você quer comunicar entendido pela audiência somente daquela maneira. Um tipo de sonho do poder - nenhum chuvisco na tela, apenas audiência totalmente passiva. Agora, meu problema é que não creio que a mensagem tenha somente um significado. Então, eu quero apostar numa noção de um poder e estruturação no momento de codificação que, não obstante, não apague todos os outros possíveis sentidos (HALL,1994, p.261 apud ESCOSTEGUY, 2001, p.76).
\end{abstract}

A partir desse trecho e do percurso realizado ao longo dessa reflexão teórica inicial podemos perceber a importância do aprofundamento dos estudos sobre a cultura midiática e sua relação com o público. Dessa forma, alguns apontamentos podem ser tecidos:

a) As narrativas são parte constitutiva da vida humana e mais do que nunca a mídia se utiliza disso para promover seus interesses (diversos);

b) O cinema e a televisão, em função das possibilidades audiovisuais ainda em expansão, se destacam como meios extremamente habilidosos na construção de narrativas e, por consequência, de imaginários e identidades;

c) Os media deveriam propagar uma pluralidade ideológica, no entanto selecionam um conjunto de representações organizadas na promoção de sentidos preferenciais;

d) Fica a cargo das audiências, então, a resistência e recriação dos conteúdos midiáticos a partir de sua própria cultura, questionando quando convier o papel ideológico assumido pelos media.

Na próxima etapa do trabalho, procederemos à análise da obra cinematográfica Que horas ela volta? (Anna Muylaert, 2015) buscando aprofundar a investigação sobre o potencial do cinema enquanto instrumento ideológico. Partindo de uma breve síntese do filme, trechos do roteiro serão destacados para elucidar e tensionar aspectos aqui levantados a partir dos aportes teóricos resgatados. 


\section{O FILME QUE HORAS ELA VOLTA?}

Com direção da cineasta Anna Muylaert, o filme Que horas ela volta? estreou em 2015 e já recebeu prêmios no Sundance Film Festival² (Prêmio Especial do Júri pela atuação das protagonistas Regina Casé e Camila Márdila) e no Festival de Berlim³ (Melhor ficção na Mostra Panorama). O longa-metragem narra a história de Val (Regina Casé), uma empregada doméstica que deixou Pernambuco para trabalhar em uma casa de família no bairro do Morumbi em São Paulo e tem sua rotina alterada com a chegada da filha Jéssica (Camila Márdila).

Bárbara (Karine Teles) e Carlos (Lourenço Mutarelli) são os patrões de Val e pais de Fabinho (Michel Joelsas). Ela trabalha com moda e ele é artista plástico, embora tenha parado de produzir. Fabinho, que é bastante apegado a Val, está terminando o ensino médio e vai prestar vestibular para arquitetura. A família recebe Jéssica e logo descobrem que ela será concorrente de Fabinho para a seleção da FAU, disputada Faculdade de Arquitetura e Urbanismo da Universidade de São Paulo (USP).

A convivência de Jéssica com Val e com a família ao longo dos dias não é fácil, pois Val quer que Jéssica se comporte como filha de empregada, respeitando limites e obedecendo as normas da casa para os funcionários. Para desgosto da mãe, Jéssica não enxerga essas regras e as questiona, provocando Val e abalando sua relação até então subserviente para com os patrões, sobretudo com a patroa. A trama acompanha os embates de mãe e filha e as transformações sofridas no ambiente familiar em função da presença da adolescente ali. Bárbara tenta agir de forma educada ao acolher Jéssica pelo afeto que sente por Val e em respeito aos anos de serviço prestados, mas reprova as investidas da menina para quebrar as normas “já conhecidas” de convivência entre patrões e empregados.

Já no primeiro dia, Bárbara percebe que Jéssica é diferente de Val, quando, ao olhar a estante da sala, ela diz que gostaria de ler um livro, fazendo com que Carlos lhe oferecesse em

\footnotetext{
${ }^{2}$ Informação disponível em: http://www.festivaldorio.com.br/br/noticias/brasileiro-i-que-horas-ela-volta-i-epremiado-no-sundance-film-festival. Acesso em: 12/12/2018.

${ }^{3}$ Informação disponível em: http://www.adorocinema.com/noticias/filmes/noticia-111737/. Acesso em: $12 / 12 / 2018$.
} 
empréstimo. Mais adiante, ela conhece o quarto de hóspedes e, novamente, provoca Carlos para que ele a convidasse a se instalar ali. Bárbara entende como invasivo o comportamento da menina e se chateia com a permissividade do marido. Durante a semana, a relação de amizade entre os dois se estreita, facilitando a circulação de Jéssica pelos demais cômodos da casa, como o ateliê de pintura dele e a mesa de refeições da sala, quando ele a convida para almoçar. Carlos a leva para conhecer o COPAN (edifício emblemático da cidade de São Paulo projetado por Oscar Niemeyer) e a FAU-USP, essa última juntamente com Fabinho. Em momentos a sós, ele se insinua para ela e demonstra que seus interesses vão além da amizade, mas Jéssica não corresponde e recusa acanhada.

Jéssica discute com Val por várias questões do dia a dia, como o pequeno quarto em que ela vive; a proximidade que pode ter ou não com os patrões; o uso dos espaços da casa e dos alimentos de geladeira. Ela não entende como Val aprendeu todas essas regras e a mãe explica que é natural, que “a pessoa já nasce sabendo". Mas Jéssica não se conforma. Em uma conversa acalorada, ela diz que não sabe como Val aguenta ser tratada como uma "cidadã de segunda classe" e a empregada logo rebate chamando-a de "metida" e dizendo que ela se acha "superior, melhor que todo mundo". Então, Jéssica se defende com firmeza: "não me acho melhor não Val, só não me acho pior”.

Val tenta a todo custo manter Jéssica na área da cozinha sob sua supervisão para evitar encontros e possíveis conflitos com a patroa, mas é contrariada ao ver sua filha dentro da piscina brincando com Fabinho e um amigo. O clima fica ainda pior nesse momento, pois Bárbara, que havia sofrido um acidente de carro, vê a cena e, após mandar todos saírem da água, liga para o serviço de manutenção pedindo que venham esvaziar a piscina. Ela diz para Val que viu um rato nadando lá.

Fabinho e Jéssica fazem a prova do vestibular e apenas a adolescente é aprovada. Bárbara se surpreende com a pontuação de Jéssica e, ao saber da notícia por Val, diz para a empregada não se animar, pois a segunda fase de provas costuma ser mais difícil. Fabinho fica triste por não ter passado, mas parabeniza Val pela conquista de Jéssica. Mais tarde, Val rompe com os próprios costumes de subserviência e decide entrar na piscina, algo que nunca tinha feito na casa dos patrões. Decide então ligar para Jéssica para dar os parabéns pelo vestibular e dizer que, finalmente, havia entrada na piscina. A personagem decidiu transgredir as próprias regras. A narrativa sugere, a partir deste ponto, que a empregada começa a adentrar em um mundo de possibilidades e compartilhar da visão de mundo da filha. Poucos dias depois, Fabinho diz a Val que vai fazer um intercâmbio fora do país. Essa notícia aliada à 
tensão pessoal provocada pelos questionamentos da filha impulsiona a empregada a pedir demissão do emprego e mudar de vida. O filme acaba com a cena de mãe e filha celebrando essa decisão.

\section{ANÁLISE DAS CENAS}

Detalharemos a seguir cinco sequências de cenas selecionadas como pontos importantes do roteiro que representam alguns dos aspectos teóricos levantados inicialmente.

\subsection{Sequência 1 - Val é "praticamente da família"}

No dia de seu aniversário, Bárbara é entrevistada na varanda de casa. A matéria fala de estilo. Val assiste a gravação em silêncio e quando finalizam o trabalho ela dá os parabéns à patroa e lhe entrega um presente: um conjunto de xícaras e uma garrafa térmica. Bárbara agradece e pede que Val guarde o presente para ser usado em uma ocasião especial. Val fala que Jéssica, sua filha, está vindo para São Paulo e pergunta se ela pode ficar na casa enquanto arruma um lugar fixo. Bárbara concorda e diz a Val que ela é "praticamente da família". Bárbara manda Val comprar um bom colchão, pois ela faz questão de pagar. Ela se despede de Val e recomenda que não se esqueça de fazer a receita de mousse dobrada para a festa mais tarde. Val vai para a cozinha e tenta arrumar o conjunto de xícaras na bandeja como mostra a embalagem. Após o jantar da noite, Val serve o café usando a garrafa térmica e as xícaras novas. Assim que percebe, Bárbara a repreende e manda pegar outra louça que trouxe de viagem da Suécia. Val resmunga sem entender porque foi advertida já que aquela era uma ocasião especial. Bárbara diz que o conjunto que ela deu vai para o Guarujá (casa de praia).

Nessa primeira sequência pudemos observar, como caracterizam Béla Balázs e Étienne Souriau, a inserção do espectador no universo diegético de Val, com sua rica caracterização de ambiente, tarefas, regras sociais e sensações. Ela tem respeito por sua patroa e agradece toda forma de afeto que possa receber, mesmo que venha por meio da compra de um colchão e seguida de uma lembrança/ordem para dobrar a receita de mousse. Bárbara delimita bem o lugar de Val. É “praticamente da família” e por isso tem o crédito para receber sua filha lá, mas desde que isso não a faça esquecer suas funções e nem seja um problema para a rotina da casa. Val sente de modo verdadeiro a rejeição da patroa pelo presente, comprado com tanto gosto. A ingenuidade da personagem não permite compreender que, 
mesmo que fosse um produto bom e caro, o fato de ter sido um presente dela faz com que não seja "permitida" a sua circulação e utilização na casa. Patrões e funcionários, nesse caso e também historicamente, não se misturam.

\subsection{Sequência 2 - "Jéssica vai ficar no quarto de hóspedes"}

Carlos e Fabinho mostram a piscina para Jéssica e depois seguem vendo os outros cômodos da casa. Jéssica se impressiona ao perceber que todos os quartos são suítes. Ela entra no quarto de hóspedes, senta na cama e comenta: "um colchão bom e ninguém dorme aqui". Carlos fala que é o quarto de hóspedes e ela pergunta se é ali então que ela vai ficar, provocando o convite. Val a repreende, mas o patrão já estava cedendo o espaço para que ela se instalasse. Ele avisa para Bárbara como quem pede autorização e ela responde chateada batendo a porta. Val tenta reverter a situação dizendo que a filha foi oferecida, mas Jéssica já anuncia que vai pegar suas coisas e logo volta. Quando a noite chega é Fabinho que vai dormir no quarto de Val e receber um cafuné.

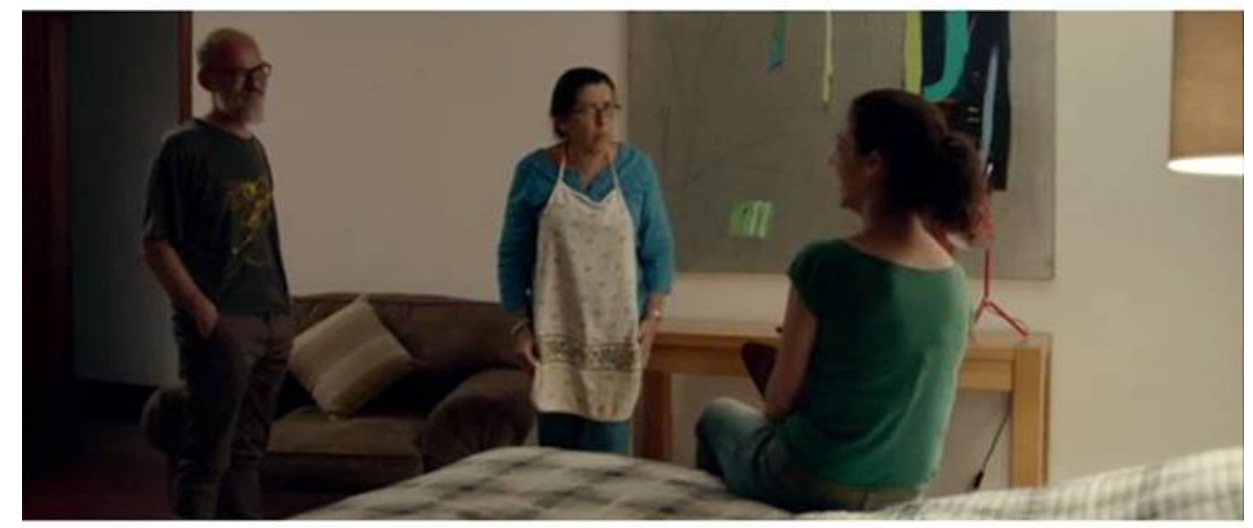

Figura 1 - Jéssica se oferece para ficar no quarto de hóspedes Fonte: Que horas ela volta (ANNA MUYLAERT, 2015)

Com essa sequência, fica evidenciada a compreensão de Val sobre o uso dos espaços da casa e a postura contestadora de Jéssica ao se enquadrar como hóspede e, portanto, apta a se instalar naquele quarto. Bárbara se comporta como o indivíduo opressor que precisa manter a "ordem" na casa demarcando território, remontando ao pensamento escravocrata de outros tempos e indicando a "bricolagem dos tempos" típica das mídias audiovisuais descrita por Martín-Barbero e Rey. Carlos comprova sua submissão e Fabinho, desprendido de apego material, busca o carinho de Val que Jéssica desprezou ao rever a mãe. 


\subsection{Sequência 3 - "Eles só oferecem por educação"}

Jéssica foi convidada por Carlos para o almoço e quando o patrão pede um café ela pergunta para Val se "tem algum docinho?". Carlos manda a empregada trazer o sorvete e ela vai buscar contrariada com o comportamento da filha. Val traz um pote de sorvete (Kibon), mas o patrão diz que ela deve trazer o outro, mais refinado, de chocolate com amêndoas (Häagen-Dazs). A empregada confirma com Carlos se é "o de Fabinho" e ele responde que é “o de chocolate com amêndoas", enfatizando que está pedindo em função do sabor, que o sorvete é de todos que quiserem. Val traz o sorvete, mas resmunga: "agora quando Fabinho quiser o sorvete..." Carlos serve Jéssica e ela aprova.

Na hora do jantar, Jéssica está sentada na mesa da cozinha enquanto vê Carlos na sala de jantar com a esposa e o filho. Fabinho pede o sorvete e, antes que Val leve, Jéssica pede um pouco. A empregada explica que o sorvete é de Fabinho, mas Jéssica insiste lembrando que Carlos falou que ela poderia tomar. Então, Val deixa tudo mais claro para a filha: “quando eles oferecem alguma coisa que é deles para a gente é só por educação. É porque eles têm certeza que a gente vai dizer não. Se for pra tomar sorvete é desse que é o nosso (Kibon)".

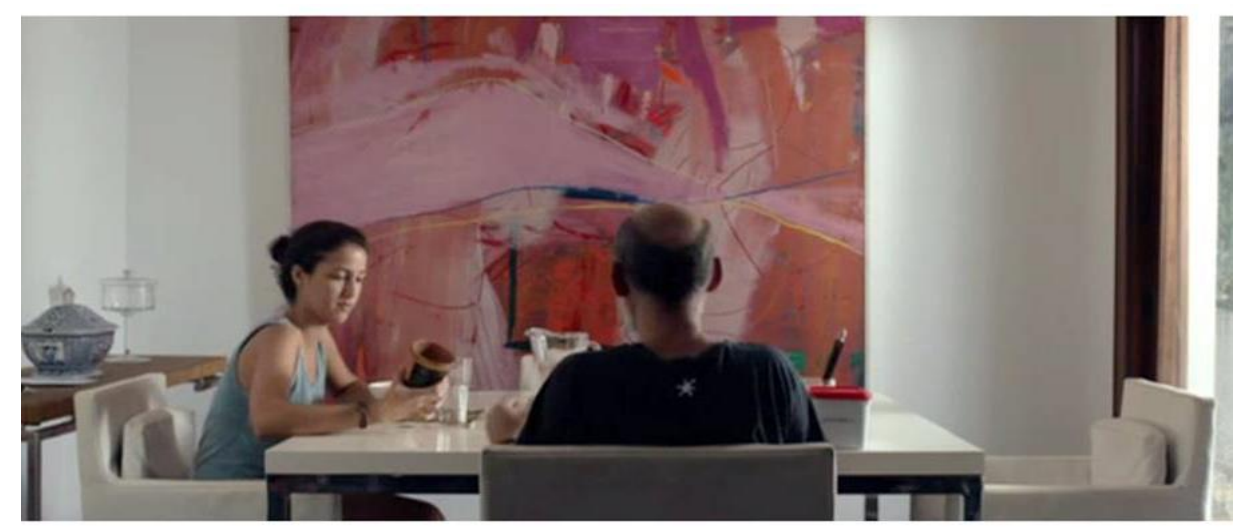

Figura 2 - Jéssica provando o sorvete Häagen-Dazs no almoço com Carlos. Fonte: Que horas ela volta (ANNA MUYLAERT, 2015).

Essa sequência nos mostra a "pedagogia cultural" mencionada por Kellner. Val explica de forma didática para Jéssica como funciona a relação com os patrões a respeito do consumo dos produtos da casa. A situação que envolve as duas marcas de sorvete explicita ainda a distinção dos produtos entre "nosso" e "deles". O filme, nesse momento, convoca os espectadores à reflexão sobre o consumo, os hábitos e privações de cada grupo social. A 
delimitação representada pelas marcas de sorvete em que uma é colocada como "mais simples" e a outra é "nobre" ou "chique" e, portanto, destinada aos funcionários e aos patrões nos faz entender que não existiria a possibilidade de transgressão da regra ou de mobilidade social através do consumo. Cada grupo tem marcas e produtos específicos. Percebemos ainda na explicação dada por Val a Jéssica que mesmo que um grupo ofereça "acesso" ao outro por meio dos produtos, não se deve aceitar, pois essa recusa seria o pressuposto da oferta.

\subsection{Sequência 4 - "Tem que estudar para passar"}

Fabinho chega da prova e diz aos pais que foi difícil. A mãe chama para conferir o gabarito. Ele não passa. Val consola Fabinho e quando Bárbara chega para abraçá-lo ele rejeita. Bárbara retruca enciumada "poxa Fabinho, a Val pode te abraçar e eu não posso" e o filho justifica "a Val me acha inteligente e você me acha burro". Val volta e dá a notícia da aprovação de Jéssica. Bárbara fica surpresa e dá parabéns. Com desdém, ela explica para Val que essa é só a primeira fase e que ela não deve ficar muito animada, pois a segunda é muito mais difícil. Fabinho não acredita que a mãe esteja falando isso. Bárbara acrescenta para Fabinho: "estudou né, não fazia outra coisa, só ficava estudando. Tem que estudar né? Pra passar? Tem que estudar”. Nesse momento Fabinho estava abraçado à mãe, mas ela se levanta e sai do quarto.

A sequência da aprovação de Jéssica é bastante significativa para o argumento central do filme que gira em torno do acesso à educação, da mobilidade social, das práticas sociais discriminatórias e da manutenção das forças vigentes. No contexto ficcional construído, Jéssica, por ser filha da empregada, não poderia passar em uma universidade pública concorrida. O sucesso dela em detrimento do fracasso de Fabinho é chocante para Bárbara que, rapidamente, tenta assustar Val e destruir sua felicidade com a questão da segunda etapa. Ela ainda pondera com o filho que Jéssica possa ter passado por que "só" fazia isso, indicando que sua condição - restrita de opções de lazer, talvez - lhe deixou mais concentrada nos estudos.

Nesse caso, o filme se coloca na contramão da ideologia unitária e expressa sua pluralidade como defendeu Escosteguy alicerçada em Hall. Jéssica é aprovada a contragosto, mas é aprovada. $\mathrm{O}$ acesso à universidade é possível. $\mathrm{O}$ esforço de estudo foi suficiente e não está relacionado à sua condição financeira.

\subsection{Sequência 5 - "Val entra na piscina"}


Val entra na piscina quase seca e liga para Jéssica. Ela lhe dá os parabéns pelo vestibular e diz onde está. Val brinca e chuta a água para que sua filha escute o barulho. Ela diz para Jéssica que está muito feliz e desliga dizendo "te amo".

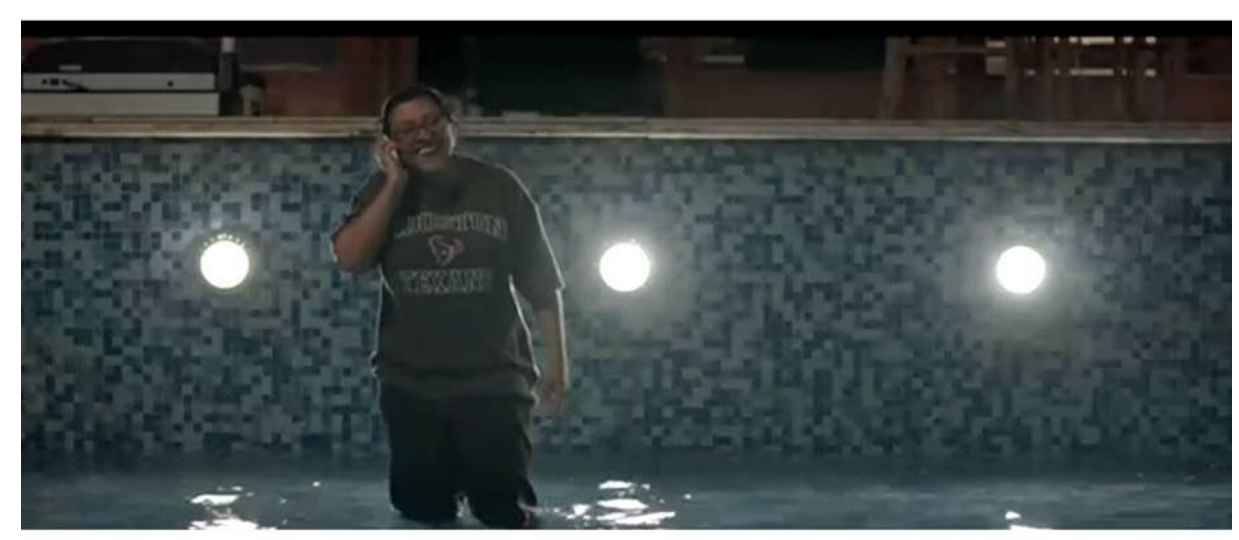

Figura 3 - Val entra na piscina e fala com Jéssica ao telefone. Fonte: Que horas ela volta (ANNA MUYLAERT, 2015).

A sequência em que Val entra na piscina prova a interferência de Jéssica na vida da mãe. Como argumentou Kellner, os espetáculos da mídia dramatizam o poder dominante. Val entra na água de forma sorrateira, como quem não quer ser descoberta e sabe que está errada, porém, está feliz e, por isso, passa por cima das regras e princípios que entende como certos. Ela liga para Jéssica e diz que está na piscina porque precisa de uma testemunha do próprio ato e porque precisa dizer para a filha que está diferente e que ela é a responsável por essa mudança.

\section{VISÕES DE CONSUMO}

É possível articular aspectos de comunicação e consumo a partir da concepção que o sujeito faz de si mesmo. O filme Que horas ela volta? permite que o espectador visualize a própria posição na sociedade e a maneira com a qual lida com aspectos práticos do consumo, como mercadorias e situações com as quais pode, deve ou é permitido ter acesso. Ao longo da trama, é possível perceber diversas dinâmicas de apropriação, importantes de serem destacadas neste momento:

a) O estilo de vida dos patrões em confronto com os benefícios oferecidos para a funcionária da casa; 
b) A empregada tem acesso a diversos itens de conforto da residência, já que é responsável pela manutenção da ordem doméstica e trafega entre eles com desenvoltura. Val está acostumada a conviver, de certa forma, com luxo e fartura, mas, todos os dias, retira-se desse universo abastado para descansar no quarto dos fundos. Em um ambiente minúsculo, percebemos que a personagem cria o próprio mundo de consumo, por meio dos itens que vem acumulando ao longo dos anos. Ela sonha em ter a própria casa um dia e, pouco a pouco, adquire utensílios para a sonhada moradia.

c) O filme demonstra que, apesar das adversidades, Val tem um repertório próprio de consumo. A trama nos apresenta aos poucos: celular, roupas de trabalho versus as de passeio, perfumes, cremes, bijuterias, acessórios de cabelo, óculos escuros. No início do filme, a personagem demonstra orgulho do que possui, já que satisfaz as próprias necessidades e permite-se adquirir algo que a faça sentir-se mais próxima do universo dos patrões, a ponto de comprar um presente que considera elegante para a patroa. É possível notar que ela usa roupas doadas pelos empregadores a partir das camisetas de bandas de rock, itens também usados pelo filho do casal. É mais uma maneira que a cineasta Anna Muylaert mostra para o espectador a conexão de afeto que a empregada tem com Fabinho.

d) Ao se mudar para a própria casa, mãe e filha demonstram acesso a um tipo de liberdade. Essa libertação se dá em um nível subjetivo, porque há questionamentos de modo de vida. Tudo é explicitado de forma imagética na trama por meio de itens domésticos: mobiliário de cozinha, mesmo que parcos, utensílios domésticos e enfeites decorativos. Val mostra com orgulho um conjunto de potes e diz que comprou de uma amiga e o faz com segurança e orgulho. Ao decorar a casa, a personagem indica que atingiu um ponto de autossuperação e está pronta para adentrar em uma nova etapa de vida.

Para Baccega (2015, p.24), "ao divulgar o consumo como valor de pertencimento, a mídia contribui para reforçar a vinculação entre consumo e cultura, criando modelos a serem seguidos (...) que conferem distinção para os seus detentores”. Segundo Rocha (2012), as reflexões acerca de comunicação e consumo na América Latina emergem a partir de pressupostos de autores como Nestor García Canclini e Jesus Martín-Barbero, que articulam um "significado social das posses materiais, cuja função essencial do consumo é sua capacidade para dar sentido, vinculando-se às práticas cotidianas e a processos de constituição identitária" (ROCHA, 2012, p. 31-32). 
Não à toa, o cinema, como dissemos anteriormente, é fator de disseminação de novas práticas cotidianas relacionadas ao consumo, levando-se em conta que estamos em uma época em que há "melhores condições para que nós, consumidores, sejamos capazes de apreciar repertórios culturais e estéticos diversos" (CANCLINI, 2008, p. 28). O filme da cineasta Anna Muylaert convoca o espectador a identificar as variadas nuances de consumo. Os pontos de observação são as relações entre empregada doméstica e empregadores; mãe e filha. Cada um carrega um repertório cultural diretamente relacionado com a capacidade de posse de bens ou aspiração a obtê-los. Além disso, o consumo aparece no longa como uma forma de "reprodução social, em que são apresentadas as formas da força de trabalho e as dinâmicas de expansão do capital" (CANCLINI, 2008, p. 47). O filme apresenta de forma determinante que "consumir é também participar de um cenário de disputas por aquilo que a sociedade produz e pelas maneiras de usá-lo, além de ser lugar de distinção e diferenciação entre classes sociais e grupos" (ibidem, p. 47).

\section{CONSIDERAÇÕES FINAIS}

Este estudo nos permitiu abordar alguns dos referenciais teóricos que versam sobre ideologia, hegemonia, Estudos Culturais, cultura da mídia e diegese fílmica. O percurso traçado nos forneceu terreno sólido para proceder à análise do filme Que horas ela volta? e a seleção de trechos representativos para a discussão proposta.

A partir da descrição das sequências, constatamos diversas temáticas que o roteiro perpassa, em sua maioria, questões polêmicas ou práticas veladas na sociedade contemporânea. Destacamos: o acesso à educação, a distinção entre as classes sociais, as práticas discriminatórias e as lutas ideológicas que se dão diariamente entre patrões e funcionários, sobretudo no âmbito doméstico. Como nos indica Martín-Barbero (2004), o estudos de comunicação na atualidade, sobretudo quando confrontados com práticas cotidianas de consumo, nos permite observar muito mais do que os meios e suas mensagens ou linguagens: as questões de fundo advêm agora dos estudos dos modelos culturais e dos locais em que são consumidos, já que o filme trata de relações sociais tipicamente brasileiras.

Conclui-se, ainda que de maneira inicial, que o papel dos meios de comunicação e, aqui, do cinema enquanto propagador e legitimador da ideologia vigente se fez notável, muito embora as reflexões propostas pela obra e os debates liderados por Jéssica tenham nos enchido de esperança quanto à possíveis mudanças ou transformações sociais. Como 
defendeu Kellner (2001), cabe ao espectador construir sua própria leitura sobre a história de Val e de outras, apropriando-se dos conteúdos midiáticos, questionando o que lhe convir e resistindo à manipulação em favor de própria cultura e valores.

\section{REFERÊECIAS}

AUSTER, Paul. Letters from America. Disponível em:

http://www.guardian.co.uk/books/2001/dec/16/fiction.paulauster. Acesso em: 08/08/2011.

BACCEGA, Maria Aparecida. Estudos de comunicação e análise do discurso. Teoria e prática. São Paulo, Intermeios; Fapesp; ESPM, 2015.

BALÁZS, Béla. A câmera criativa. In: XAVIER, Ismail (Org.). A experiencia do cinema: antologia. Rio de Janeiro: Edições Graal, 1983.

BARBERO, Jesús Martín. Ofício de cartógrafo. Travessias latino-americanas da comunicação na cultura. São Paulo, Edições Loyola, 2004.

BARTHES, Roland et. al. Análise estrutural da narrativa: pesquisas semiológicas. Tradução de Maria Zélia Barbosa Pinto. Petrópolis: Vozes, 1976.

BEZERRA, Beatriz Braga. O product placement no cinema brasileiro. 2014. 146 f. Dissertação (Mestrado em Comunicação) - Universidade Federal de Pernambuco, Recife, 2014.

BRUNER, Jerome. The narrative construction of reality. Critical Inquiry. Chicago, v.1, n. 18, agosto. 1991. Disponível em: http://www.jstor.org/stable/1343711?seq=1\#page_scan_tab_contents. Acesso em: 20/10/2015.

CANCLINI, Néstor Gárcia. Consumidores y ciudadanos. Conflictos multiculturales de la globalización. México, Random House Mondadori, 2012.

. Leitores, espectadores e internautas. São Paulo, Iluminuras, 2008.

CHACEL, Marcela Costa da Cunha. Narrativas transmidiáticas como ferramentas de comunicação entre as marcas e os novos consumidores. 2012. $131 \mathrm{f}$. Dissertação (Mestrado em Comunicação) - Universidade Federal de Pernambuco, Recife. 2012.

ESCOSTEGUY, Ana Carolina. Cartografias dos Estudos Culturais: uma versão latino-americana. Belo Horizonte: Autêntica, 2001.

HALL, Stuart. Culture, the media and the ideological effect. In: CURRAN, J. et al. (orgs.), Mass Communication and Society, London: Edward Arnold, 1977, p. 315-48.

Reflections upon the Encoding/Decoding model: An interview with Stuart Hall. In:

CRUZ, Jon e LEWIS, Justin (orgs.), Viewing, Reading, Listening - Audiences and Cultural

Reception, Boulder/San Francisco/Oxford: Wetview Press, 1994, p. 253-274.

. Da diáspora: identidade e mediações culturais. Belo Horizonte: Editora UFMG, 2003 
KELLNER, Douglas. A cultura da mídia. Estudos culturais: identidade e política entre o moderno e o pós-moderno. Tradução de Ivone Castilho Benedetti. Bauru: EDUSC, 2001.

MARTÍN-BARBERO, Jésus; REY, Germán. Os exercícios do ver: hegemonia audiovisual e ficção televisiva. Tradução de Jacob Gorender. São Paulo: Editora Senac São Paulo, 2004.

ROCHA, Rose de Melo. A pureza impossível: consumindo imagens, imaginando o consumo. In:

ROCHA, Rose de Melo e CASAQUI, Vander. Estéticas midiáticas e narrativas do consumo. Porto Alegre, Sulina, 2012.

SOURIAU, Étienne. L’univers filmique. Paris: Flammarion Éditeur, 1953.

TODOROV, Tzvetan. As categorias das narrativas literárias. In: BARTHES, Roland. et. al. Análise estrutural da narrativa: pesquisas semiológicas; tradução de Maria Zélia Barbosa Pinto. Petrópolis: Vozes, 1976.

Original recebido em: 25 de novembro de 2016

Aceito para publicação em: 08 de abril de 2018

Beatriz Braga Bezerra

Publicitária e doutora pelo Programa de Comunicação e Práticas do Consumo da Escola Superior de Propaganda e Marketing - ESPM. Integrante do Grupo CNPq de Pesquisa em Subjetividade, Comunicação e Consumo do PPGCOM/ESPM

Dorama de Miranda Carvalho

Jornalista e doutora pelo Programa de Comunicação e Práticas do Consumo da Escola Superior de Propaganda e Marketing - ESPM. Integrante do Grupo CNPq de Pesquisa Comunicação, Consumo e Arte do PPGCOM-ESPM.

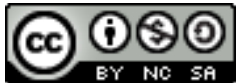

Esta obra está licenciado com uma Licença

Creative Commons Atribuição-NãoComercial-CompartilhaIgual 4.0 Internacional 